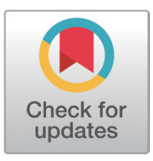

Received: Jul 4, 2021

Revised: Aug 20, 2021

Accepted: Sep 1, 2021

\#These authors contributed equally to this work.

*Corresponding author

Sang-lk Oh

Division of Animal Diseases \& Health,

National Institute of Animal Science,

Rural Development Administration,

Wanju 55365, Korea.

Tel: +82-63-238-7228

E-mail: ohsangik@korea.kr

Copyright @ 2021 Korean Society of Animal Sciences and Technology.

This is an Open Access article distributed under the terms of the Creative Commons Attribution

Non-Commercial License (http:// creativecommons.org/licenses/bync/4.0/) which permits unrestricted non-commercial use, distribution, and reproduction in any medium, provided the original work is properly cited.

ORCID

Jae-Hee Roh

https://orcid.org/0000-0003-4223-1096 Ngoc Anh Bui

https://orcid.org/0000-0002-3233-5265 Hu Suk Lee

https://orcid.org/0000-0002-8731-9836 Vuong Nghia Bui

https://orcid.org/0000-0001-5499-9305

Duy Tung Dao

https://orcid.org/0000-0001-6421-7223

Thanh Thi Vu

https://orcid.org/0000-0003-1047-443X

\section{Age-dependent immune response in pigs against foot-and-mouth disease virus in vitro}

Jae-Hee Roh ${ }^{1,2 \#}$, Ngoc Anh Bui ${ }^{3 \#}$, Hu Suk Lee ${ }^{4 \#}$, Vuong Nghia Bui ${ }^{3}$, Duy Tung Dao ${ }^{3}$, Thanh Thi Vu ${ }^{3}$, Thuy Thi Hoang ${ }^{3}$, Kyoung-Min So ${ }^{1}$, Seung-Won $\mathrm{Yi}^{1}$, Eunju Kim ${ }^{1}$, Tai-Young Hur ${ }^{1}$ and Sang-lk Oh ${ }^{1 *}$

${ }^{1}$ Division of Animal Diseases \& Health, National Institute of Animal Science, Rural Development Administration, Wanju 55365, Korea

${ }^{2}$ Department of Pet Health, Kwangju Women's University, Gwangju 62396, Korea

${ }^{3}$ Virology Department, National Institute of Veterinary Research, Hanoi 100000, Vietnam

${ }^{4}$ International Livestock Research Institute (ILRI), Hanoi 111111, Vietnam

\section{Abstract}

Foot-and-mouth disease, one of the most contagious diseases in cloven-hoofed animals, causes significant economic losses. The pathogenesis of foot-and-mouth disease virus (FMDV) infection is known to differ with age of the animals. In this study, we aimed to reveal the difference in immunological response in the initial stage of FMDV infection between piglets and adult pigs. Peripheral blood mononuclear cells (PBMCs) were isolated from 3 piglets ( 8 weeks old) and 3 pigs ( 35 weeks old) that were not vaccinated against FMDV. O-type FMDV $\left(2 \times 10^{2}\right.$ median tissue culture infectious dose) was inoculated into porcine PBMCs and the cells were incubated at $37.0^{\circ} \mathrm{C}$ under $5 \% \mathrm{CO}_{2}$ for various time periods $(0,1,3,6,12,24$, and $48 \mathrm{~h})$. The total RNA was obtained from the FMDV-inoculated PBMCs after each time point, and the virus titer was investigated in these RNA samples. Furthermore, dynamics of mRNA expression of the six tested cytokines (interferon [IFN]- $\alpha$, IFN- $\gamma$, înterleukin [IL]-6, IL-8, IL-10, and tumor necrosis factor [TNF]- $\alpha$ ) in FMDV-inoculated porcine PBMCs were evaluated by time-series analysis to determine the differences, if any, based on the age of the pigs. The PBMCs of piglets contained the highest quantity of FMDV mRNA at 6 hours post-inoculation (hpi), and the PBMCs of pigs had the highest quantity of FMDV mRNA at $3 \mathrm{hpi}$. The mean cycle threshold-value in the PBMCs steadily decreased after the peak time point in the piglets and pigs ( 6 and 3 hpi, respectively). The dynamics of mRNA expression of all cytokines except TNF- $\alpha$ showed age-dependent differences in FMDV-inoculated PBMCs. The mRNA expression of most cytokines was more pronounced in the piglets than in the pigs, implying that the immune response against FMDV showed an age-dependent difference in pigs. In conclusion, within $48 \mathrm{hpi}$, the 8-week-old piglets responded more rapidly and were more sensitive to FMDV infection than the 35-week-old pigs, which could be associated with the difference in the pathogenesis of FMDV infection among the pigs. These results provide valuable insights into the mechanisms underlying the age-dependent differences in immune response in pigs against FMDV infection.

Keywords: Foot-and-mouth disease, Foot-and-mouth disease virus, Peripheral blood mononuclear cell, Pig, Immune response, Age-dependent 
Thuy Thi Hoang

https://orcid.org/0000-0002-1162-288X

Kyoung-Min So

https://orcid.org/0000-0001-9497-3345

Seung-Won Yi

https://orcid.org/0000-0001-5545-2969

Eunju Kim

https://orcid.org/0000-0003-4040-0474

Tai-Young Hur

https://orcid.org/0000-0003-3129-2942

Sang-lk Oh

https://orcid.org/0000-0003-0877-9170

Competing interests

No potential conflict of interest relevant to

this article was reported.

Funding sources

This work was carried out with the support of the "Cooperative Research Program for Agriculture Science and Technology Development (Project title: Development of immune enhancement technology by investigating resistance factors for ASF and foot-and-mouth disease virus infection, Project No. PJ01491201)", Rural Development Administration, Korea

\section{Acknowledgements}

The authors thank the National Institute of Veterinary Research (NIVR) of the Ministry of Agriculture and Rural Development (MARD), Vietnam. The authors are also grateful to Ngo Thi Minh Quyen and Myoung-Geum Kang for their technical support.

Availability of data and material Upon reasonable request, the datasets of this study can be obtained from the corresponding author.

\section{Authors' contributions \\ Conceptualization: Roh JH. \\ Data curation: Oh SI. \\ Formal analysis: Roh JH, Oh SI. \\ Methodology: Roh JH, Bui NA, Bui VN, Dao \\ DT, Oh SI. \\ Software: Oh SI \\ Validation: So KM, Yi SW, Kim E, Hur TY, Oh SI. Investigation: Roh JH, Bui NA, Bui VN, Vu \\ TT, Hoang TT, Oh SI. \\ Writing - original draft:, Roh JH, Oh SI. \\ Writing - review \& editing: Roh JH, Lee HS, \\ Bui VN, Oh SI.}

Ethics approval and consent to participate This experimental study followed the guidelines approved by the Animal Ethics Committee of the National Institute of Animal Science (NIAS), Korea and the rules of the National Institute of Veterinary Research (NIVR), Vietnam. The study was approved by the Institutional Animal Care and Use Committee (IACUC) of the NIAS, Korea (approval number: NIAS 2020-465).

\section{INTRODUCTION}

Foot-and-mouth disease (FMD) is a highly contagious disease, associated with high morbidity in cloven-hoofed animals, including cattle, goats, sheep, and pigs. FMD causes substantial economic and production losses worldwide, and it has been listed first in the class A diseases of the animal health code by the World Organisation for Animal Health [1-3]. The etiological agent, FMD virus (FMDV), is a small, non-enveloped, single stranded, positive-sense RNA virus belonging to the genus Aphthorirus of the family Picornaviridae. The virus is grouped into seven serotypes $(\mathrm{O}, \mathrm{A}$, C, SAT1, SAT2, SAT3, and Asia1), and its high mutation rate could lead to extensive variation within serotypes $[3,4]$. There is no significant difference in the clinical signs of infection by these serotypes, but there is almost no cross-immunity [5]. Among the seven serotypes, outbreaks of serotype A and O FMDV are frequently reported in various Asian countries, including Vietnam, Korea, and China [6].

The clinical signs commonly observed in adult FMDV-infected pigs are vesicular epithelial lesions, high morbidity (up to 100\%), and negligible mortality rate (approximately 1\%) [1,7,8]. However, the mortality rate has been reported to be approximately 40\% in piglets during an FMDV epidemic in Taiwan and China [9]. Viral myocarditis, which results in heart failure, is known to be the major cause of death in acute FMDV infection in piglets [9,10]. A previous case study reported that two FMDV-exposed piglets (weighing approximately $20 \mathrm{~kg}$ ) died 3 and 5 days after exposure, respectively [10]. Considering these facts, we hypothesized that immunological response at the initial phase of FMDV infection differs between piglets and adult pigs.

The host immune response against viral infection has been demonstrated to be modulated by complex and divergent pathway [11]. Therefore, understanding the immunological interactions between the host and the pathogen is essential to provide a novel approach for the potential control of FMDV infection. During the early phase of viral infection, the innate immune response is initiated, mediated largely by white blood cells such as natural killer (NK) cells, dendritic cells (DCs), and macrophages [12,13]. Peripheral blood mononuclear cells (PBMCs) are known to play a significant role in the immune system, as they contain a mixed population of T-cells, B-cells, NK cells, DCs, and macrophages. Therefore, PBMCs are key cells that induce an innate and adaptive immune response through the expression of various cytokines [12].

The objective of this study was to investigate the effect of age on the immunological response against FMDV in porcine PBMCs. Furthermore, we compared the time-series of quantities of FMDV RNAs in PBMCs from pigs of different age groups. To the best of our knowledge, this is the first study to report the age-dependent differences in the expression of cytokines in FMDVinoculated porcine PBMCs. This study could provide a better understanding of the mechanisms underlying the host immune responses to evaluate the age-dependent immune responses in FMDV-infected pigs.

\section{MATERIALS AND METHODS}

\section{Ethics statement}

The protocols used for the experimental procedures were reviewed and approved by the Institute Animal Care and Use Committee of National Institute of Animal Science (approval number: NIAS 2020-465).

\section{Animals and blood collection}

Three adult Vietnamese pot-bellied pigs (age 35 weeks and average weight $75 \mathrm{~kg}$ ) and three piglets (age 8 weeks and average weight $7 \mathrm{~kg}$ ), not vaccinated against FMDV, were obtained from 
the same herd from a commercial pig farm. All pigs were confirmed serologically negative for the following five pathogens: FMDV, porcine circovirus 2, porcine reproductive and respiratory syndrome virus, classical swine fever virus, and African swine fever virus. Animals were maintained with a commercial diet twice daily, and water was provided ad libitum. Blood samples $(10 \mathrm{~mL})$ were collected aseptically from pigs into a $\mathrm{K}_{2}$ ethylene-diamine-tetraacetic acid (EDTA) vacuum tube by puncturing the vena cava, and immediately transported to the biosafety laboratory of the National Institute of Veterinary Research, Vietnam.

Peripheral blood mononuclear cell isolation and foot-and-mouth disease virus inoculation The collected blood sample was diluted 1:1 with phosphate-buffered saline (Sigma-Aldrich, St. Louis, MO, USA), and then used to obtain PBMCs by density-gradient centrifugation with FicollPaque $^{\text {TM }}$ Plus ( $1.077 \mathrm{~g} / \mathrm{mL}$, Cytiva Life Sciences, Uppsala, Sweden). Five milliliters of diluted blood was added to $4 \mathrm{~mL}$ of Ficoll-Paque ${ }^{\mathrm{TM}}$ Plus (Cytiva Life Sciences) and centrifuged at 1,200×g for 20 min at $20^{\circ} \mathrm{C}$. After centrifugation, the PBMC layer found at the interface between the plasma and Ficoll-Paque ${ }^{\mathrm{TM}}$ Plus (Cytiva Life Sciences) was collected. Cells were stained with trypan blue and counted using a plastic disposable C-Chip Neubauer Improved hemocytometer (DHC-No. 1, InCyto, Cheonan, Korea). The PBMCs were resuspended in RPMI 1640 medium (R7388, Sigma-Aldrich) containing 10\% fetal bovine serum (FBS) and $100 \mathrm{U} / \mathrm{mL}$ penicillin and $100 \mu \mathrm{g} / \mathrm{mL}$ streptomycin mixture (Sigma-Aldrich), and seeded in 24-well plates at a density of $2.0 \times 10^{6}$ cells $/ \mathrm{mL}$.

The serotype O FMDV, isolated in 2003 from pigs in Gia Lai Province, Vietnam, was provided by the National Institute of Veterinary Research, Vietnam. Virus titration in BHK-21 cells was used to determine the median tissue culture infectious dose $\left(\mathrm{TCID}_{50}\right)$ per milliliter of FMDV according to a previous study [14]. PBMCs, except the mock infection control group, were infected with $2.0 \times 10^{2} \mathrm{TCID}_{50}$ of FMDV in RPMI 1640 and incubated for various time periods $(0,1,3,6$, 12,24 , and $48 \mathrm{~h}$ ) in a humidified incubator with $5 \% \mathrm{CO}_{2}$ at $37.0^{\circ} \mathrm{C}$.

\section{Total RNA extraction and cDNA synthesis}

The total RNA was isolated from the infected and non-infected PBMCs using the RNeasy Mini Kit (Qiagen, Hilden, Germany) according to the manufacturer's instructions. RNA concentration was determined using a Nanodrop I spectrophotometer (Thermo Fisher Scientific, Hanover Park, IL, USA). RNA from each group was reverse transcribed into cDNA in a $20-\mu \mathrm{L}$ reaction mixture using the RT2 First Strand Kit (Qiagen) containing random primers following the instructions provided in the user's manual.

\section{Foot-and-mouth disease virus detection from RNAs of peripheral blood mononu- clear cells}

FMDV RNA in PBMCs were detected using the ABI 7500 real-time polymerase chain reaction (PCR) System (Applied Biosystems, Foster City, CA, USA) with a commercial FMDV diagnostic kit (VDx FMDV qRT-PCR Kit, Median Diagnostics, Chuncheon, Korea). RNA $(5 \mu \mathrm{L})$ was added into a tube containing $10 \mu \mathrm{L}$ of $2 \times$ master mix and $5 \mu \mathrm{L}$ of $4 \times$ oligo mix, and the reaction conditions were as follows: step $1,50^{\circ} \mathrm{C}$ for $30 \mathrm{~min}$; step $2,95^{\circ} \mathrm{C}$ for $15 \mathrm{~min}$; step 3,40 cycles at $95^{\circ} \mathrm{C}$ for $10 \mathrm{~s}$ and $60^{\circ} \mathrm{C}$ for $30 \mathrm{~s}$. The probe was labeled with a $5^{\prime}$-reporter dye (fluorescein amidites).

\section{Real-time quantitative polymerase chain reaction analysis}

The relative expression of genes in PBMCs was quantified and compared at each time point ( 0 , 1, 3, 6, 12, 24, and $48 \mathrm{~h}$ ) after FMDV infection. The amplification reactions were carried out in a customized RT2 Profiler PCR Array (Qiagen) manufactured with primer sets for the specified 
genes pre-dispensed into a 96-well PCR plate. After mixing the cDNA with RT2 SYBR Green ROX qPCR Master Mix (Qiagen), $25 \mu \mathrm{L}$ of the mixture containing cDNA was dispensed into each well of PCR arrays. Real-time PCR was performed on an ABI 7500 Real-Time PCR System (Applied Biosystems) under the following conditions: $10 \mathrm{~min}$ at $95^{\circ} \mathrm{C}, 40$ cycles at $95^{\circ} \mathrm{C}$ for $15 \mathrm{~s}$ and at $60^{\circ} \mathrm{C}$ for $1 \mathrm{~min}$. Dissociation curve analyses were performed immediately after each PCR run using the instrument's default setting. The gene list for the custom RT2 Profiler PCR Array in this study is presented in Table 1. Expression fold change was determined using the $2^{-\Delta \Delta \mathrm{Ct}}$ method with glyceraldehyde-3-phosphate dehydrogenase (GAPDH) as the endogenous reference gene to normalize the level of target gene expression [15].

\section{Statistical analysis}

All experiments had three replicates. The results are expressed as mean \pm SEM. Statistical analyses were performed using SPSS version 26.0 (IBM, Armonk, NY, USA). Data were analyzed using an unpaired Student's $t$-test to compare the mean values between two experimental groups at the same time point. Results with $p<0.05$ were considered statistically significant.

\section{RESULTS}

Time-series detection of foot-and-mouth disease virus RNA in peripheral blood mononuclear cells from piglets and pigs

The expression of viral mRNA in PBMCs of piglets (8-week-old, $n=3$ ) and pigs (35-week-old, $n$ $=3$ ) was analyzed after FMDV inoculation. The dynamics of cycle threshold-value (cycle threshold $\left[\mathrm{C}_{\mathrm{T}}\right]$-value, mean $\pm \mathrm{SEM}$ ) of PBMCs of the piglets and pigs are shown in Fig. 1. The FMDV mRNA level in PBMCs from piglets (8-week-old) increased from 1 (average $\mathrm{C}_{\mathrm{T}}$-value $=24.58 \pm$ $0.97)$ to 6 hpi $(23.95 \pm 1.05)$, and then the concentration substantially decreased until $48 \mathrm{hpi}$ (25.89 \pm 1.32 ). In PBMCs from pigs (35-week-old), the viral mRNA level substantially increased from 1 (average $\mathrm{C}_{\mathrm{T}}$-value $\left.=24.58 \pm 1.21\right)$ to $3 \mathrm{hpi}(23.84 \pm 0.99)$, and then steadily decreased until $48 \mathrm{hpi}$ $(25.41 \pm 1.30)$.

Dynamics of cytokine expression against foot-and-mouth disease virus infection in porcine peripheral blood mononuclear cells

The dynamics of mRNA transcription of the six tested cytokines (interferon [IFN]- $\alpha$, IFN- $\gamma$,

Table 1. List of primers specific for porcine cytokines and their characteristics as analyzed by real-time $P_{C R}{ }^{1)}$

\begin{tabular}{|c|c|c|c|c|}
\hline Gene symbol & Cytokine (description) & Sequence $\left(5^{\prime} \rightarrow 3^{\prime}\right)$ & Accession no. & Qiagen ID \\
\hline IFNA1 & $\begin{array}{l}\text { IFN- } \alpha \\
\text { (Interferon-alpha-15) }\end{array}$ & $\begin{array}{l}\text { F: CTCTCTGGGCTGCGACCT } \\
\text { R: CTCCTTCCTCCTGAGTCTGTC }\end{array}$ & NM_001164845 & PPS02420A \\
\hline IFNG & $\begin{array}{l}\text { IFN-y } \\
\text { (Interferon-gamma) }\end{array}$ & $\begin{array}{l}\text { F: TTCAGCTTTGCGTGACTTTG } \\
\text { R: GGTCCACCATTAGGTACATCTG }\end{array}$ & NM_213948 & PPS00334A \\
\hline IL6 & $\begin{array}{l}\text { IL-6 } \\
\text { (Interleukin-6) }\end{array}$ & $\begin{array}{l}\text { F: CCTCTCCGGACAAAACTGAA } \\
\text { R: TCTGCCAGTACCTCCTTGCT }\end{array}$ & NM_001252429 & PPS19379A \\
\hline CXCL8 & $\begin{array}{l}\text { IL-8 } \\
\text { (Interleukin-8) }\end{array}$ & $\begin{array}{l}\text { F: GACCCCAAGGAAAAGTGGGT } \\
\text { R: TGACCAGCACAGGAATGAGG }\end{array}$ & NM_213867 & PPS00237A \\
\hline IL10 & $\begin{array}{l}\text { IL-10 } \\
\text { (Interleukin-10) }\end{array}$ & $\begin{array}{l}\text { F: CTGCCTCCCACTTTCTCTTG } \\
\text { R: TCAAAGGGGCTCCCTAGTTT }\end{array}$ & NM_214041 & PPS00445B \\
\hline TNF & $\begin{array}{l}\text { TNF- } \alpha \\
\text { (Tumor necrosis factor) }\end{array}$ & $\begin{array}{l}\text { F: CCACGCTCTTCTGCCTACTGC } \\
\text { R: GCTGTCCCTCGGCTTTGAC }\end{array}$ & NM_214022 & PPS00426A \\
\hline
\end{tabular}

${ }^{11}$ Two endogenous control genes-glyceraldehyde-3-phosphate dehydrogenase (GAPDH, Qiagen ID: PPS00192A) and $\beta$-actin (ACTB, Qiagen ID: PPS00953A) — present on the PCR array were used for normalization.

$\mathrm{PCR}$, polymerase chain reaction. 


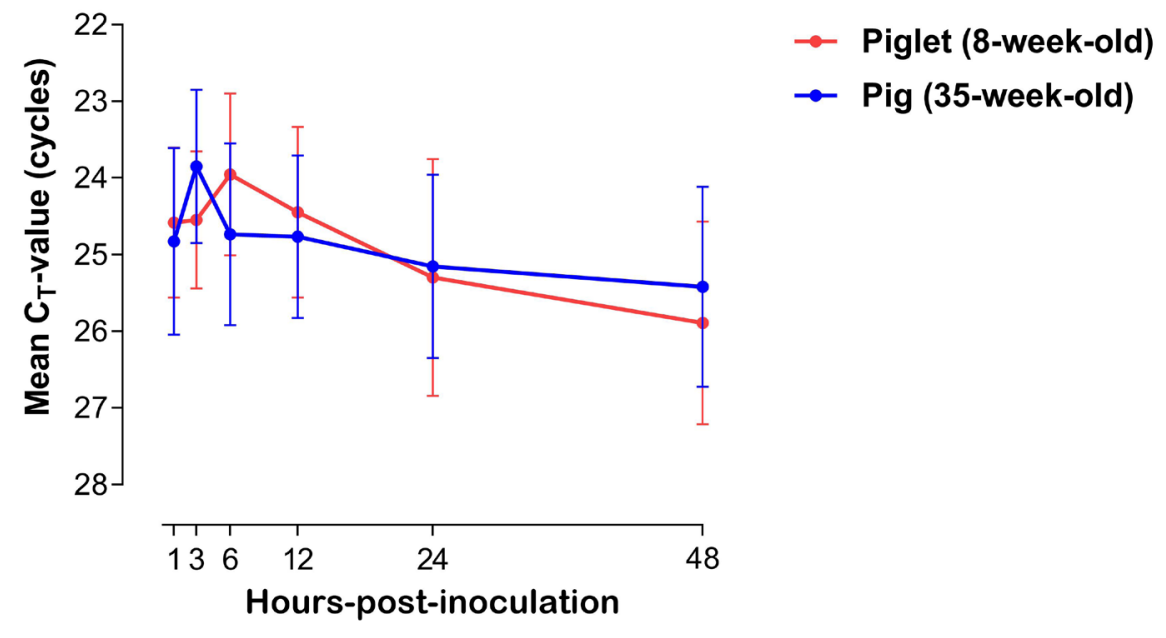

Fig. 1. Comparison between the mean $C_{T}$-values of FMDV-infected porcine PBMCs of Vietnamese potbellied piglets (8-week-old, $n=3$ ) and pigs ( 35 -week-old, $n=3$ ). $C_{T}$, cycle threshold; FMDV, foot-and-mouth disease virus; PBMC, peripheral blood mononuclear cells.

interleukin [IL]-6, IL-8, IL-10, and tumor necrosis factor [TNF]- $\alpha$ ) in porcine PBMCs in response to FMDV infection were analyzed at various time points to determine any difference between the experimental age groups (Fig. 2). The level of each cytokine was assessed at 0,1,3,6, 12,24 , and $48 \mathrm{~h}$ using an SYBR Green-based real-time PCR assay, and all of them were induced by FMDV inoculation within $1 \mathrm{~h}$ in PBMCs from both groups. All tested cytokines (except TNF- $\alpha$ ) derived from PBMCs showed age-dependent differences in the pattern of induction. The mean fold induction of IFN- $\alpha$ expression in the PBMCs from piglets was rapidly increased from $12(1.22 \pm 0.50)$ to $24 \mathrm{hpi}(3.84 \pm 2.56)$ and declined at 48 hpi ( $0.23 \pm 0.16$ fold). Regarding IFN- $\gamma$ expression in piglets, the mean fold induction was substantially increased at $24 \mathrm{~h}(11.76 \pm 1.54)$. In PBMCs from pigs, IFN- $\alpha$ mRNA expression varied throughout the experiment period, and rapidly increased at $48 \mathrm{hpi}(5.22 \pm 3.69$ fold). IFN $\gamma$ expression in PBMCs from pigs showed an increasing trend until $48 \mathrm{~h}$ after FMDV infection. The fold induction values in IFN- $\alpha$ showed significant differences between the age groups at 6 and $24 \mathrm{hpi}$, and those in IFN- $\gamma$ were significantly different at 24 hpi. IL-6 expression in PBMCs of both age groups increased progressively, with the maximum fold induction at $6 \mathrm{hpi}$ in piglets $(19.15 \pm 9.03)$ and $12 \mathrm{hpi}$ in pigs $(8.37 \pm 4.44$ fold $)$, and then steadily declined until 48 hpi (piglets [3.77 \pm 1.17$]$ and pigs [0.23 \pm 0.05 fold]). At 1 and 48 hpi, the mean fold induction of IL-6 mRNA expression in the two age groups showed a significant difference. The IL-8 and IL-10 gene expression levels in PBMCs of both age groups peaked at 24 hpi (IL-8 in piglets [38.05 \pm 12.16$]$ and pigs [3.04 \pm 1.05$]$, IL-10 in piglets [18.29 \pm 9.08$]$ and pigs [5.10 \pm 2.23 fold] $)$ and decreased at 48 hpi (IL- 8 in piglets [19.16 \pm 0.87$]$ and pigs [ $2.31 \pm 1.11]$, IL-10 in piglets [4.34 \pm 1.48$]$ and pigs $[1.59 \pm 0.40$ fold]). The fold induction values of IL-8 showed significant differences between the groups at 24 and $48 \mathrm{hpi}$, and those of IL-10 were significantly different at 1,3 , and 48 hpi. The fold induction of TNF- $\alpha$ gene expression showed similar trends in both groups, showing a substantial increase from 12 to $24 \mathrm{hpi}$ and a decline at $48 \mathrm{hpi}$.

\section{DISCUSSION}

The severity of clinical signs of FMDV infection is inversely related to the age of pig $[9,16]$. Piglets 

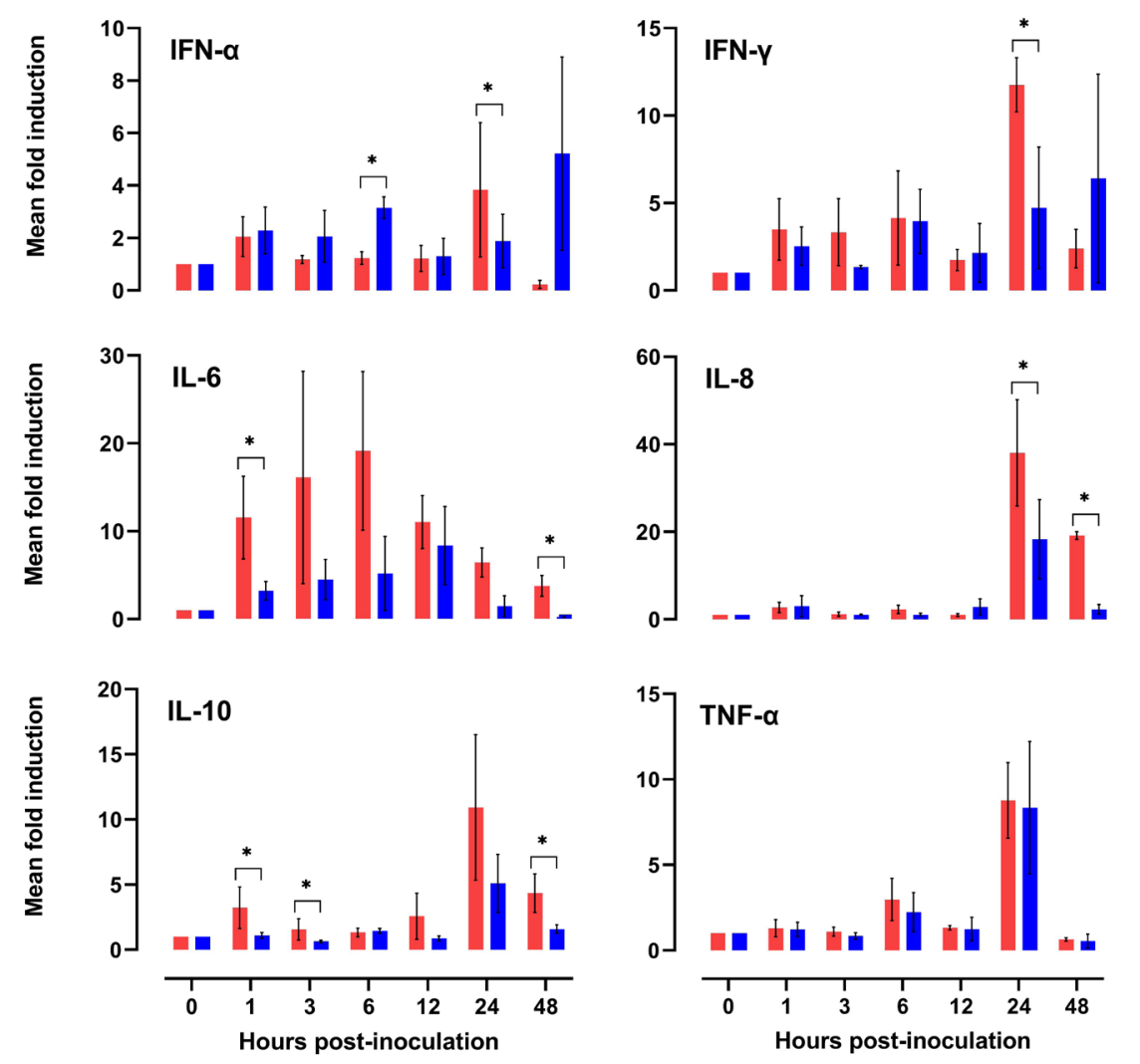

Piglet (8-week-old)

Pig (35-week-old)

Fig. 2. Dynamics of cytokine mRNA transcription in porcine PBMCs inoculated with FMDV antigen. PBMCs isolated from Vietnamese pot-bellied piglets (8-week-old, $n=3$ ) and pigs (35-week-old, $n=3$ ) were inoculated with $2 \times 10^{2} \mathrm{TCID}_{50}$ FMDV $\mathrm{O}$ antigen for $0,1,3,6,12,24$, and $48 \mathrm{~h}$. The extracted RNAs were analyzed using real-time PCR. Results are expressed as fold changes of cytokine mRNA transcription in FMDVinoculated cells compared with that in the non-inoculated cells in media. GAPDH was used as internal control and mRNA levels at $0 \mathrm{~h}$ were used as calibrators. ${ }^{*} p<0.05$. IFN, interferon; IL, interleukin; TNF, tumor necrosis factor; $\mathrm{C}_{\mathrm{T}}$, cycle threshold; PBMC, peripheral blood mononuclear cells; FMDV, foot-and-mouth disease virus; $\mathrm{TCID}_{50}$, tissue culture infectious dose; PCR, polymerase chain reaction; GAPDH, glyceraldehyde-3-phosphate dehydrogenase.

aged up to 14 weeks, and particularly those aged less than 8-weeks may die without developing any clinical signs of FMD, due to heart failure, characterized by acute or hyper-acute myocarditis [17]. A comparison of cytokine mRNA expression in 8- and 35-week-old pigs could explain the agerelated difference in the severity of FMDV infection. In this study, we investigated the changes in viral load in porcine PBMCs after FMDV infection and analyzed the dynamics of expression of relevant cytokines, such as IFN- $\alpha$, IFN- $\gamma$, IL-6, IL-8, IL-10, and TNF- $\alpha$, in PBMCs from piglets (8-week-old) and pigs (35-week-old) to understand the age-related difference in immune response against FMDV infection in the initial stages.

In general, in vitro analysis of cytokine expression in PBMCs against viral infection is a widely used method to study immune responses in host animals [18]. Although PBMCs are not regarded as a main target of FMDV, they are reportedly suitable for characterizing host immune responses against FMDV infection $[9,18]$. In this study, the time-series amounts of RNAs from FMDVinfected porcine PBMCs were compared between piglets and pigs. No significant changes were observed between them, and FMDV RNAs could be detected in the PBMCs of both age groups 
within an hour after FMDV inoculation. Through these results, we could confirm that PBMCs were successfully infected with FMDV, and the infected cells would appropriately respond to viral infection via secreting various cytokines. Peak detection of FMDV antigens was comparatively delayed in the PBMCs of piglets (maximum at $6 \mathrm{hpi}$ ) compare with those of the pigs (maximum at $3 \mathrm{hpi}$ ). The mean $\mathrm{C}_{\mathrm{T}}$-value in porcine PBMCs inoculated with FMDV steadily decreased in both age groups after their respective peak time points. These findings suggest that there was an age-related difference in the intracellular infection period of the virus or virus suppression by the immune response. However, a general conclusion could not be drawn regarding the age-dependent FMDV susceptibility in pigs, as these results were obtained only from in vitro experiments. Therefore, further in vivo studies are needed to clarify the pattern of viral replication in FMDVinfected pigs of different age groups.

Innate immunity is the first host defense system against infectious diseases [19]. PBMCs are the gatekeepers against virus spread resulting from systemic viral infections and include many subpopulations that might cooperate in the immune activation processes [20]. In case of FMDV, the virus has been demonstrated to modulate the host immune response by using several mechanisms, implying that it is important to understand the host-pathogen interactions [11]. Cytokine response should be analyzed to understand the host immunological mechanisms against viral infections [21,22].

Type-I interferons are known to be the first line of host cell defense against viral infections, which inhibit viral replication in susceptible cells [23-25]. IFN- $\alpha$ is known to be a key factor for rapid resistance to FMDV infection [26,27]. Early IFN- $\alpha$ production induces virus-susceptible cells refractory to infection, thereby preventing viral replication and spread within the host, and resulting in a rapid reduction of viremia [27]. In this study, IFN- $\alpha$ mRNA expression in PBMCs was more pronounced in the 35-week-old pigs than in the 8-week-old piglets until $12 \mathrm{~h}$ after FMDV inoculation. Delayed IFN- $\alpha$ response in PBMCs from piglets caused adverse effects on the initial immune response against FMDV infection. IFN- $\gamma$ is another important cytokine that regulates the immune response against FMDV infection and inhibits FMDV replication in vitro [28]. The dynamics of IFN- $\gamma$ mRNA expression in the two age groups showed similar patterns with those of IFN- $\alpha$. This result was compatible with the fact that IFN- $\alpha$ activates NK cells, which kill the FMDV-infected cells and secrete IFN- $\gamma$ [29]. IFN- $\gamma$ and TNF- $\alpha$ are the major pro-inflammatory cytokines that activate T-cells, the main effector cells for viral clearance, via the Th1 pathway [30]. Therefore, TNF- $\alpha$ is known to be an essential mediator of inflammation and is known to facilitate the transition from innate to adaptive immunity [19]. The current results showed that there was no significant difference in TNF- $\alpha$ mRNA expression between the two age groups, and it was the most pronounced in both groups at $24 \mathrm{hpi}$.

IL-6 is a pleotropic cytokine that is produced in response to tissue damage and infections [31]. The biological consequences of IL-6 production have been associated with both pro- and antiinflammatory effects [32], highlighting the pivotal role of IL-6 in the activation and regulation of immune response [33]. The upregulation of IL-6 was observed in the PBMCs of piglets at all tested time points, and the corresponding mean fold induction was significantly higher in piglets than in the pigs, at 1 hpi. Increased levels of IL-6 may exacerbate the immunopathology by cytokine secretion and cellular recruitment. In fact, this condition of increased inflammation may be an advantage for some viruses by providing them with new cellular targets for subsequent viral infections [33]. To date there is no scientific evidence to support the causal relationship between IL-6 levels and pathogenicity of FMDV. However, a recent study suggested that infection by Picornaviridae members induces IL-6 expression in various cardiac-resident cells, which might contribute to damage to cardiomyocytes via acute inflammation [9]. This implies that IL-6, which 
reacted more strongly in piglets than in pigs, may be a clue to explain the age-related difference in pathogenicity against FMDV. IL-8 is a chemotactic factor for all migratory immune cells. The level of IL-6 along with IL-8 increases in pigs vaccinated against FMDV [34,35]. Here, the IL-8 mRNA expression level showed no substantial variation until 12 hpi; thereafter, it rapidly increased at 24 and 48 hpi in FMDV-inoculated PBMCs from piglets and pigs, respectively. The mRNA expression level of IL-8 was considerably higher in PBMCs from the piglets than those from the pigs, after 24 hpi. IL-10 has important anti-inflammatory functions to prevent unnecessary tissue damage caused by the immune system [36]. In addition, the diminished $\mathrm{T}$ cell response during FMDV infection is known to be related to the elevated level of IL-10 produced by DCs [11]. Given that IL-10 mRNA expression was observed to be significantly higher in piglet PBMCs than in pig PBMCs in the early stages of viral infection (1 and $3 \mathrm{hpi})$ in this study, piglets may have a weaker T-cell-mediated cellular response than pigs.

Here, we investigated age-dependent cytokine expression patterns against FMDV infection in porcine PBMCs and elucidated the immune responses to FMDV infection in pigs. These findings imply that the immune response against FMDV infection is age dependent. However, the study had two major limitations. First, FMDV-inoculated pigs are known to show peak viremia at 24-48 hpi, with full clearance by 96 hpi [27]. However, the present study was only performed until 48 hpi, which may not fully reflect the immune response against FMDV infection. Therefore, further studies are needed to analyze the dynamics of cytokine mRNA expression until at least $96 \mathrm{hpi}$. Second, the number of animals, from which PBMCs were obtained, was relatively small to establish a definitive conclusion. In addition, as this study involved an in vitro experiment targeting PBMCs from pigs, it may not accurately reflect the overall age-dependent immune responses of pigs infected with FMDV. Future in vivo studies with a large number of animals are essential to understand the host defense mechanisms against FMDV infection in pigs, and further transcription analyses could also provide valuable information for improving our awareness of host cell-FMDV interactions.

In conclusion, FMDV mRNA expression in PBMCs was not consistent between 8- and 35-week-old pigs, and this may be associated with the differences in the expression patterns of cytokine mRNAs in porcine PBMCs between the two age groups. The expression dynamics of immune-regulating cytokine genes, except that of TNF- $\alpha$, in the FMDV-inoculated porcine PBMCs were different in pigs of the two age groups. Only IFN- $\alpha$ showed a rapid initial response in adult pigs, and all other cytokine mRNAs showed higher expression in the PBMCs of piglets than in those of adult pigs. In addition, IL-6 mRNA expression was more pronounced in piglets than in pigs in the very early stage of FMDV infection, which may be related to the occurrence of acute myocarditis in young pigs. The results suggest that there is a difference in the cytokinemediated immune response against FMDV infection between piglets and pigs, which may explain the age-related differences observed in pigs with respect to the pathogenesis of FMDV. Further in vivo studies may help validate this conclusion.

\section{REFERENCES}

1. OIE [World Organisation for Animal Health]. Principles and methods of validation of diagnostic assays for infectious diseases [Internet]. 2013 [cited 2021 Apr 7]. https://www.oie.int/ fileadmin/Home/eng/Health_standards/aahm/current/1.1.02_VALIDATION.pdf

2. Brown F. The history of research in foot-and-mouth disease. Virus Res. 2003;91:3-7. https:// doi.org/10.1016/S0168-1702(02)00268-X

3. Grubman MJ, Baxt B. Foot-and-mouth disease. Clin Microbiol Rev. 2004;17:465-93. https:// doi.org/10.1128/CMR.17.2.465-493.2004 
4. Domingo E, Baranowski E, Escarmís C, Sobrino F. Foot-and-mouth disease virus. Comp Immunol Microbiol Infect Dis. 2002;25:297-308. https://doi.org/10.1016/S01479571(02)00027-9

5. Carrillo C, Tulman ER, Delhon G, Lu Z, Carreno A, Vagnozzi A, et al. Comparative genomics of foot-and-mouth disease virus. J Virol. 2005;79:6487-504. https://doi.org/10.1128/ JVI.79.10.6487-6504.2005

6. Pirbright Institute. Country reports [Internet]. 2021 [cited 2021 Apr 7]. http://www.wrlfmd. org/country-reports

7. León EA. Foot-and-mouth disease in pigs: current epidemiological situation and control methods. Transboundary Emerging Dis. 2012;59:36-49. https://doi.org/10.1111/j.18651682.2011.01290.x

8. Alexandersen S, Zhang Z, Donaldson AI, Garland AJM. The pathogenesis and diagnosis of foot-and-mouth disease. J Comp Pathol. 2003;129:1-36. https://doi.org/10.1016/S00219975(03)00041-0

9. Zhang Z, Waters R, Li Y. Pathogenesis of non-epithelial foot-and-mouth disease in neonatal animals. Vet Microbiol. 2021;254:108961. https://doi.org/10.1016/j.vetmic.2020.108961

10. Stenfeldt C, Pacheco JM, Borca MV, Rodriguez LL, Arzt J. Morphologic and phenotypic characteristics of myocarditis in two pigs infected by foot-and mouth disease virus strains of serotypes O or A. Acta Vet Scand. 2014;56:42. https://doi.org/10.1186/s13028-014-0042-6

11. Stenfeldt C, Diaz-San Segundo F, de los Santos T, Rodriguez LL, Arzt J. The pathogenesis of foot-and-mouth disease in pigs. Front Vet Sci. 2016;3:41. https://doi.org/10.3389/ fvets.2016.00041

12. Kirthika P, Ali MA, Behera P, Subudhi PK, Tolenkhomba TC, Gali JM. Dynamics of cytokine gene expression in peripheral blood mononuclear cells of indigenous and exotic breeds of pigs in India. Anim Sci J. 2017;88:1794-800. https://doi.org/10.1111/asj.12827

13. Aderem A, Ulevitch RJ. Toll-like receptors in the induction of the innate immune response. Nature. 2000;406:782-7.https://doi.org/10.1038/35021228

14. Reed LJ, Muench H. A simple method of estimating fifty per cent endpoints. Am J Epidemiol. 1938;27:493-7. https://doi.org/10.1093/oxfordjournals.aje.a118408

15. Pfaff MW. A new mathematical model for relative quantification in real-time RT-PCR. Nucleic Acids Res. 2001;29:e45. https://doi.org/10.1093/nar/29.9.e45

16. Ryan E, Horsington J, Durand S, Brooks H, Alexandersen S, Brownlie J, et al. Foot-andmouth disease virus infection in young lambs: pathogenesis and tissue tropism. Vet Microbiol. 2008;127:258-74. https://doi.org/10.1016/j.vetmic.2007.08.029

17. Kitching RP, Alexandersen S. Clinical variation in foot and mouth disease: pigs. Rev Sci Tech. 2002;21:513-8. https://doi.org/10.20506/rst.21.3.1367

18. Zhao FR, Xie YL, Liu ZZ, Shao JJ, Li SF, Zhang YG, et al. Transcriptomic analysis of porcine PBMCs in response to FMDV infection. Acta Trop. 2017;173:69-75. https://doi.org/10.1016/ j.actatropica.2017.05.009

19. Li W, Mao L, Shu X, Liu R, Hao F, Li J, et al. Transcriptome analysis reveals differential immune related genes expression in bovine viral diarrhea virus-2 infected goat peripheral blood mononuclear cells (PBMCs). BMC Genom. 2019;20:516. https://doi.org/10.1186/s12864019-5830-y

20. Colavita F, Bordoni V, Caglioti C, Biava M, Castilletti C, Bordi L, et al. ZIKV infection induces an inflammatory response but fails to activate types I, II, and III IFN response in human PBMC. Mediators Inflamm. 2018;2018:2450540. https://doi.org/10.1155/2018/2450540

21. Parida S, Oh Y, Reid SM, Cox SJ, Statham RJ, Mahapatra M, et al. Interferon- $\gamma$ production in 
vitro from whole blood of foot-and-mouth disease virus (FMDV) vaccinated and infected cattle after incubation with inactivated FMDV. Vaccine. 2006;24:964-9. https://doi.org/10.1016/ j.vaccine.2005.08.108

22. Dar PA, Hajam IA, Suryanarayana VS, Kishore S, Kondabattula G. Kinetics of cytokine expression in bovine PBMCs and whole blood after in vitro stimulation with foot-and-mouth disease virus (FMDV) antigen. Cytokine. 2015;72:58-62. https://doi.org/10.1016/j.cyto.2014.12.011

23. Samuel CE. Antiviral actions of interferons. Clin Microbiol Rev. 2001;14:778-809. https://doi. org/10.1128/CMR.14.4.778-809.2001

24. Guo HC, Liu ZX, Sun SQ Leng QW, Li D, Liu XT, et al. The effect of bovine IFN- $\alpha$ on the immune response in guinea pigs vaccinated with DNA vaccine of foot-and-mouth disease virus. Acta Biochim Biophys Sin (Shanghai). 2004;36:701-6. https://doi.org/10.1093/ abbs/36.10.701

25. Goodbourn S, Didcock L, Randall RE. Interferons: cell signalling, immune modulation, antiviral response and virus countermeasures. J Gen Virol. 2000;81:2341-64. https://doi. org/10.1099/0022-1317-81-10-2341

26. Chinsangaram J, Moraes MP, Koster M, Grubman MJ. Novel viral disease control strategy: adenovirus expressing alpha interferon rapidly protects swine from foot-and-mouth disease. J Virol. 2003;77:1621-5. https://doi.org/10.1128/JVI.77.2.1621-1625.2003

27. Nfon CK, Toka FN, Kenney M, Pacheco JM, Golde WT. Loss of plasmacytoid dendritic cell function coincides with lymphopenia and viremia during foot-and-mouth disease virus infection. Viral Immunol. 2010;23:29-41. https://doi.org/10.1089/vim.2009.0078

28. Zhang ZD, Hutching G, Kitching P, Alexandersen S. The effects of gamma interferon on replication of foot-and-mouth disease virus in persistently infected bovine cells. Arch Virol. 2002;147:2157-67. https://doi.org/10.1007/s00705-002-0867-6

29. Toka FN, Nfon CK, Dawson H, Estes DM, Golde WT. Activation of porcine natural killer cells and lysis of foot-and-mouth disease virus infected cells. J Interferon Cytokine Res. 2009;29:179-92. https://doi.org/10.1089/jir.2008.0058

30. de León P, Cañas-Arranz R, Defaus S, Torres E, Forner M, Bustos MJ, et al. Swine T-cells and specific antibodies evoked by peptide dendrimers displaying different FMDV T-cell epitopes. Front Immunol. 2021;11:621537. https://doi.org/10.3389/fimmu.2020.621537

31. Tanaka T, Narazaki M, Kishimoto T. IL-6 in inflammation, immunity, and disease. Cold Spring Harb Perspect Biol. 2014;6:a016295. https://doi.org/10.1101/cshperspect.a016295

32. Scheller J, Chalaris A, Schmidt-Arras D, Rose-John S. The pro- and anti-inflammatory properties of the cytokine interleukin-6. Biochim Biophys Acta Mol Cell Res. 2011;1813:878-88. https://doi.org/10.1016/j.bbamcr.2011.01.034

33. Velazquez-Salinas L, Verdugo-Rodriguez A, Rodriguez LL, Borca MV. The role of interleukin 6 during viral infections. Front Microbiol. 2019;10:1057. https://doi.org/10.3389/ fmicb.2019.01057

34. Cox SJ, Aggarwal N, Statham RJ, Barnett PV. Longevity of antibody and cytokine responses following vaccination with high potency emergency FMD vaccines. Vaccine. 2003;21:1336-47. https://doi.org/10.1016/S0264-410X(02)00691-6

35. Gowane GR, Sharma AK, Sankar M, Narayanan K, Bisht P, Subramaniam S, et al. The expression of IL6 and 21 in crossbred calves upregulated by inactivated trivalent FMD vaccine. Anim Biotechnol. 2014;25:108-18. https://doi.org/10.1080/10495398.2013.834826

36. Lannes N, Summerfield A. Regulation of porcine plasmacytoid dendritic cells by cytokines. PLOS ONE. 2013;8:e60893. https://doi.org/10.1371/journal.pone.0060893 